\title{
MAPPING SAND LAYERS IN CLAYEY TILL USING CROSSHOLE GROUND-
} PENETRATING RADAR

\author{
Authors: M.C. Looms ${ }^{1}$, A. Klotzsche ${ }^{2}$, J. van der Kruk ${ }^{2}$, T.H. Larsen ${ }^{3}$, A. Edsen ${ }^{3}$, N. \\ Tuxen $^{4}$, N. Hamburger ${ }^{4}$, J. Keskinen ${ }^{1}$, and L. Nielsen ${ }^{1}$.
}

Full names and e-mails of authors: Majken Caroline Looms: mcl@geo.ku.dk, Anja Klotzsche: a.klotzsche@fz-juelich.de, Jan van der Kruk: j.van.der.kruk@fz-juelich.de, Thomas Hauerberg Larsen: thla@orbicon.dk, Anders Edsen: edsn@orbicon.dk, Nina Tuxen: nina.tuxen@regionh.dk, Nancy Hamburger: nancy.hamburger@regionh.dk, Johanna Keskinen: keskinen@ign.ku.dk, and Lars Nielsen: 1n@ign.ku.dk.

Affiliations: 1) Department of Geosciences and Natural Resource Management, University of Copenhagen, Øster Voldgade 10, 1350, Copenhagen, Denmark. 2) Agrosphere IBG-3, Forschungszentrum Jülich GmbH, Wilhelm-Johnen-Straße, 52428 Jülich, Germany. 3) Orbicon, Ringstedvej 20, 4000 Roskilde, Denmark. 4) Capital Region of Denmark, Center for Regional Development, Kongens Vænge 2, 3400 Hillerød, Denmark.

Original paper date of submission: May 16th, 2017

Revised paper date of submission: September $14^{\text {th }}, 2017$ 


\section{ABSTRACT}

Fluid transport through clayey tills governs the quantity and quality of groundwater resources in the Northern hemisphere. This transport is often controlled by a three-dimensional network of macropores (biopores, fractures and sand lenses) within the clayey till. At present, a non-destructive technique that can map and characterize the sand-lens-network does not exist, and full excavation or extensive drilling is therefore the only solution. Acquisition and modeling of crosshole ground penetrating radar (GPR) may provide the answer to this problem. We collected one- and two-dimensional crosshole GPR data at a field site in Denmark between four 8-m-deep boreholes with horizontal distances varying between $2.64-5.05 \mathrm{~m}$. We show that the depth, thickness, and tilt of a coherent sand layer within the clayey till (approximately $0.4-0.6 \mathrm{~m}$ thick) as well as the underlying sand formation can be mapped accurately using the GPR data. We identified the sand efficiently as a highly resistive section with high electromagnetic wave velocities, while the clayey till was conductive with lower electromagnetic wave velocities. We found that the exact location of the sand occurrences was better delineated by the increase in amplitude than the increase in electromagnetic wave velocity. We believe that crosshole GPR may contribute significantly to groundwater protection and contaminant remediation initiatives.

\section{INTRODUCTION}

In the Northern hemisphere, large parts of the superficial geology consist of glacial deposits that originate from the late Pleistocene glaciations (McCabe 1987; Shaw 1987; Houmark-Nielsen, 2007; 2010). Knowledge of the water flow and transport pathways through these glacial deposits is necessary in order to sustainably exploit and protect our groundwater 
reservoirs. In clayey till, the presence of macropores dominates the transport pathways. These macropores exist as fractures, biopores from burrows and roots, as well as sand lenses (Keller et al., 1986; McKay et al., 1993; Sidle et al., 1998; Jakobsen and Klint, 1999; Klint and Gravesen, 1999; Broholm et al., 2000; Nilsson et al., 2001; Jørgensen et al., 2002). To date, focus has in particular been on mapping fractures and biopores, while the existence and influence of centimeter-to-meter-scale sand lenses have almost been overlooked (Gravesen et al., 2014). However, sand lenses may create a three-dimensional network of pathways that enables much faster transport of water and contaminants than through the surrounding fine-grained diffusionlimited clay matrix (Kessler et al., 2012). Furthermore, the contaminants may be transported over a much greater horizontal area than predicted using the overall geological and hydrological parameters (Kessler, 2012). The sand-lens-network is non-trivial to map and at present a lowcost non-invasive technique does not exist.

Instead, extensive drilling or detailed description of cliff faces (Kessler et al., 2012) can be used to extract information on the macropore network. Three-dimensional information is nonetheless difficult, extensive and time-consuming to obtain, and often results in a full excavation of the site (e.g., Klint and Gravesen, 1999). Full excavation is not possible for urban areas or contaminated sites and excludes time-lapse investigations of flow and transport. Crosshole ground penetrating radar (GPR) is a high-resolution geophysical method, where an electromagnetic (EM) wave is emitted from one borehole antenna and recorded at a receiver antenna in a second borehole (Hubbard et al., 1997). The recorded EM signal provides information on the electrical permittivity and the electrical conductivity of the investigated formation, that can be related to velocity and the attenuation of the EM wave, respectively (Annan, 2005). To date, published field studies using crosshole GPR only include sediments with 
low electrical conductivity, e.g., unconsolidated sands (Cassiani et al., 2006; Irving et al., 2007;

Haarder et al., 2015; Looms et al., 2008; Klotzsche et al., 2010; Gueting et al., 2015), sandstone (Binley et al., 2002), and chalk (Keskinen et al., 2017). In general, clayey environments have been avoided as the attenuation of the EM signal reduces the signal strength and thereby the possible distance between boreholes.

In this study, crosshole GPR data is, for the first time, used to map sand-lens occurrences within an unsaturated clayey till. The low water retention properties of sand result in a lower soil moisture and therefore a higher EM velocity than in the surrounding wetter clay. Furthermore, the contrast between the electrical conductivity of dry sand and wetter clay affects the attenuation of the EM signal.

\section{FIELD SITE}

The field site is located at the most eastern edge of the Kallerup gravel pit, Denmark. Geological borehole information available from the nearby area indicates 15-30 m glacial sediments on top of limestone/chalk deposists (Jupiter database: http://www.geus.dk/DK/datamaps/jupiter). The glacial deposits originate from the Weichselian glaciation and were deposited in connection with the main advance from the Baltic region (Houmark-Nielsen, 1989). A very thorough description of the sand-lens occurrences at the field location was performed by Kessler et al. (2012).

In November 2015, four access tubes for crosshole GPR data collection were drilled resulting in six borehole-pair combinations. The distances of these six combinations range between 2.64-5.05 m. A 0.4-0.6 m thick sand occurrence was observed in all drill cuttings at 
approximately 1.40-2.35 m depth within the clayey till. Furthermore, sand occurrences were found below $6.11 \mathrm{~m}-6.75 \mathrm{~m}$ depth. The sand occurrences are interpreted to be a coherent sand sheet and the Hedeland meltwater formation, respectively, similar to the findings of Kessler et al. (2012). For all the subsequent data analysis, the depths are relative to the ground-surface level at borehole RT1, approximately $34.53 \mathrm{~m}$ above sea level.

\section{METHODS}

\section{Crosshole GPR}

Crosshole GPR measurements were collected using $100 \mathrm{MHz}$ borehole antennae (PulseEKKO system from Sensors \& Software, ON, Canada). Three different measurement surveys were used: 1) calibration gather in air, 2) equidistant-offset transmitter-receiver profiling or zero-offset profile (ZOP), where the transmitter antenna and the receiver antenna are moved in parallel, and 3) multiple-offset gather (MOG), where the data are collected with different transmitter-receiver antenna-offsets resulting in crossing wave pathways (Annan, 2005).

Calibration gathers were collected holding both antennae in air and increasing the antenna separation from $1.00 \mathrm{~m}$ to $4.00 \mathrm{~m}$ at $0.10 \mathrm{~m}$ increments (a total of 31 traces). The exact time the transmitter emits energy (known as absolute time zero) can be determined using this gather type, as the velocity of the emitted electromagnetic wave can be assumed to travel at the speed of light through air (i.e., $0.3 \mathrm{~m} / \mathrm{ns}$ ) (Oberröhrmann et al., 2013). A calibration gather was collected before and after each ZOP (seven in total) and four times during the MOG data collection in order to account for equipment drift over time. 
During the ZOP data acquisition, we used an increment of $0.0625 \mathrm{~m}$ down the boreholes and measured between 1.50-7.75 m depth (a total of 101 traces). A ZOP, including the corresponding calibration gather, took between 11 and 20 minutes to collect. All six possible ZOPs were collected.

For the MOG data collected in this study, we chose to collect a full MOG gather between 1.00 and $7.00 \mathrm{~m}$ depth with $0.25 \mathrm{~m}$ depth increments between antenna positions ( 25 fixed transmitter positions with 25 different receiver positions, 625 traces in total). Such a MOG survey took 80 minutes to collect and was only collected between boreholes RT1 and RT3. For a later inversion, we removed traces with an acquisition angle from the horizontal greater than 45 degrees in order to avoid data affected by waveguiding along the antennae (Irving and Knight, 2005). The final MOG dataset used in the inversion, therefore, comprises 466 traces.

\section{GPR post-processing and inversion}

The first-arriving energy and the amplitude of the first positive cycle were found using a semi-automated MATLAB routine. The trace energy, defined as the sum of the squared amplitudes (e.g., Klotzsche et al., 2014), could instead have been used. But for the purpose of the analysis presented here, the amplitude of the first positive cycle gives an adequate representation of the trace energy, and is more robust to non-stationary low-frequency noise. For the ZOP measurements, the traveltime, $t$, of the EM wave was converted to an EM wave velocity, $v$, by accounting for the straight wavepath distance. The MOG dataset was used both for a simple amplitude analysis and a full-waveform GPR inversion analysis. 
The full-waveform inversion (FWI) approach used for this work is the FWI algorithm of Meles et al. (2010), which extended the work of Ernst et al. (2007) by honoring the EM vector character and introducing a simultaneous updating of the electrical permittivity and conductivity. Important parts of the pre-processing procedure include a 3D-to-2D conversion of the field data and an estimation of the source wavelet. Both procedures are dependent on the electrical permittivity and conductivity starting models and must therefore be re-done when these are altered. A comprehensive description of how to apply the FWI approach to field data can be found in Klotzsche et al. (2010) and Keskinen et al. (2017).

Finally, we use the two-dimensional finite-difference time domain forward solver of the FWI algorithm to test the effect of reducing the sand lens to $0.12 \mathrm{~m}$ thickness, and whether the sand lens is coherent or interrupted between the boreholes.

\section{RESULTS}

\section{One-dimensional profiles}

In Figure 1a, we present the ZOP collected between boreholes RT1 and RT3. The traces are normalized to the maximum recorded amplitude, but are otherwise only time-zero corrected. We found that a standard dewow correction (Gerlitz et al., 1993) did not remove all lowfrequency noise and resulted in an undesirable precursor. The five additional ZOPs are not included here but show similar tendencies to the presented data. In all ZOPs, a signal is recorded throughout the investigated depth-range. At depth intervals of 1.5-3.0 m depth, as well as below $5.5 \mathrm{~m}$, the signal arrives earlier and is less attenuated than at the other depth intervals. In Figure 
1a we also present profiles of the EM velocity and the normalized amplitude of the first positive cycle. Furthermore, the observed drill cuttings from RT1 and RT3 are included in the figure.

The depth interval represented by the lowest traveltime (i.e., the higher EM velocity) corresponds to the sand occurrences in the drill cuttings. As expected, the signal is also less attenuated at these depths due to the lower soil moisture of the sand, but also the lower bulk electrical conductivity. Note that the elongated wavetrains within the sand layers indicate the presence of multiples and the occurrence of waveguiding within the sand layers. Since this highvelocity sand layer is present in low-velocity clay, the waveguide cannot be a low-velocity waveguide but would be a leaky waveguide (see also van der Kruk et al., 2009). The exact boundaries of the sand occurrences are not sharp in the EM velocity profile, as the signal arriving first at the receiver at depths near the sand occurrence is not the direct wave through the clayey till, but instead a critically refracted head wave in the till that is emitted by the fast-wave traveling signal in the sand layer. In contrast, the amplitude of the refracted wave is significantly reduced compared to the amplitude of the direct signal through sand, and the sand occurrences are therefore better identified using the amplitude of the EM wave. Overall, the results in Figure 1 clearly show that it is possible to identify sand layers in unsaturated clayey till at the Kallerup field site of approximately $0.4-0.6 \mathrm{~m}$ thickness using crosshole GPR.

Figure 1 inserted here.

At the Kallerup gravel pit, the sand layer at 1.40-2.35 m depth is expected to be coherent and between 0.4-0.6 m thick (Kessler et al., 2012). We wish to explore whether crosshole GPR can be used to map very thin sand layers (down to $0.12 \mathrm{~m}$ thickness) or identify areas where the sand layer is not coherent, but instead interrupted between the boreholes. To this end we use the 
forward solver from the FWI routine (see section on GPR post-processing and inversion), and the estimated source wavelet obtained in the full-waveform analysis (see section on Twodimensional analysis). Furthermore, the relative dielectric permittivity is assumed to be 5 and 12.6 for the unsaturated sand and clayey till, respectively, corresponding to an EM wave velocity of $0.134 \mathrm{~m} / \mathrm{ns}$ and $0.085 \mathrm{~m} / \mathrm{ns}$. The electrical conductivity is assumed to be $10 \mathrm{mS} / \mathrm{m}$ and 40 $\mathrm{mS} / \mathrm{m}$ for the unsaturated sand and clayey till, respectively, corresponding to an electrical resistivity of $100 \Omega \mathrm{m}$ and $25 \Omega \mathrm{m}$. The resulting synthetic ZOP measurements using three different synthetic models are shown Figure $1 \mathrm{~b}-\mathrm{c}$.

Synthetic model 1 in Figure $1 \mathrm{~b}$ represents the conditions at Kallerup gravel pit as it assumes a coherent sand layer between RT1 and RT3, corroborated later during excavation of the site. In order to connect the sand occurrences observed in the drill cuttings at the boreholes, the sand layer tilts slightly downwards towards RT3, and the Hedelund sand formation tilts slightly upwards towards RT3.The synthetic ZOP data exhibit overall trends similar to the collected field data in Figure 1a. First of all, the depth intervals of the sand occurrences are characterized by relatively high EM velocities and low attenuation of the first peak. Further, the attenuation effect is able to better delineate the exact depths of the sand occurrences as the amplitude is dampened significantly both when the first arriving energy has traveled through the clayey till but also when it results from refracted EM waves. The effect on the EM velocity is smoother, affecting GPR data collected up to $0.5 \mathrm{~m}$ away from the sand layer.

Synthetic model 2 in Figure 1c represents the case where the sand layer is only $0.12 \mathrm{~m}$ thick (corresponding to the cell size). Despite the thin layer, the velocity of first-arriving wave is highly affected by the sand occurrence. However, the effect on the amplitude of the signal is not 
easily discernable and could easily be missed if the depth increment of the ZOP strategy is too coarse. The results of synthetic model 2 are perhaps surprising, and were therefore corroborated using a different full-waveform GPR forward solver (Irving and Knight, 2006) (not shown here).

Finally, synthetic model 3 in Figure 1d represents the case where the sand lens is not coherent, but instead interrupted between the boreholes by a vertical $0.12 \mathrm{~m}$ clayey till section. This scenario represents the most challenging subsurface structure to identify and is of particular interest as an interrupted sand lens would potentially have major consequences for the flow and transport pathways. The effect of this vertical clay section is minor, reducing the velocity and the amplitude of the EM wave slightly, $2 \%$ or $0.003 \mathrm{~m} / \mathrm{ns}$ and $17 \%$, respectively. It would not therefore be possible using this type of analysis and data gather (ZOP) to distinguish this scenario from the case where the sand is coherent. However, the effect on the synthetic data is present, and may therefore potentially be exploited using more advanced data analysis.

\section{Two-dimensional analysis}

In order to see whether the tilt of the sand lens can be identified, we analyze the MOG data using a simple amplitude analysis based on the amplitude values of the first positive peak. This approach is similar to the work of Klotzsche et al. (2014). Here, traces having amplitude values below and above $15000 \mathrm{mV}$ are assumed to have travelled through clay and sand, respectively. We stress that this amplitude cut-off value is chosen arbitrarily and subjectively and cannot be transferred to other field sites. At the given site, the cut-off value represents approximately the mean amplitude value of the EM wave travelling through only sand and clayey till. Changing the cut-off value between 10000 and $20000 \mathrm{mV}$ does not change the result markedly. The tilts of the two sand occurrences show up clearly in Figure 2a. Nonetheless, 
similar to the analyzed ZOP data above, this type of analysis does not contribute with information regarding the coherence of the sand lens.

Figure 2 inserted here.

Finally, we use the collected MOG data in a FWI algorithm. We have chosen to include only the FWI result after 10 iterations. The aim of this study is to show the potential of the GPR data by illustrating the information content and sensitivity of the collected GPR data. We do not aim for obtaining the best, final, and most likely representation of the subsurface at Kallerup field site as this is beyond the scope of this paper. As a result, we do not therefore present the details of the inversion, including the estimated final source wavelet, the root-mean-square plot of the data misfit, or a presentation of the modelled and measured radargrams.

A low-resolution starting model (e.g., the ray-based inversion result) is typically used in the FWI algorithm such that only the data content is driving the updating of the models. However, the starting model should also yield synthetic data within half a wavelength of the measured data to guarantee a successful FWI (Meles et al., 2011). The ray-based inversion result of the MOG data from Kallerup (not shown here) provides a very smooth model of the subsurface and as a result the half-wavelength criterion is violated in the vicinity of the sand occurrences. We choose instead to use a detailed starting model based on the available borehole information and the amplitude analysis shown in Figure 2a.

The starting model and the result of running the FWI algorithm 10 iterations are shown in Figure 2b-c. Despite the highly informed dielectrical permittivity and electrical conductivity starting models, the GPR data contains additional information. After just 10 iterations, the 
corresponding subsurface models contain variability within the sand and clayey till sections and the data misfit is decreased from $1.7003 \times 10^{-6}$ to $1.1696 \times 10^{-6}$ (approximately $31 \%$ ). The internal structures within the clayey till section are particularly clear with lower conductivity values observed between 4-6 m depth (yellow colors). Even though a thorough grain-size analysis was not made at the site, large boulders and more sandy till was observed at similar depths during a subsequent excavation, which could explain this observation.

\section{CONCLUSION}

The use of crosshole ground penetrating radar to map sand lenses and internal structures in clayey till may constitute a major leap forward in the characterization and predictive modeling in such environments with significant benefits for groundwater protection and contaminant remediation initiatives.

We have shown that it is possible to use crosshole GPR to detect sand occurrences at the Kallerup gravel pit in Denmark. The sand lens and the Hedeland sand formation affected the electromagnetic wave velocity due to the lower retention properties of the sand compared to the clayey till. But also the amplitude of the electromagnetic signal was increased significantly at the sand occurrences due to the lower electrical conductivity of the sand. The distinction between sand and clayey till may therefore also be possible under saturated conditions. However, the added water will decrease the amplitude of the electromagnetic signal markedly.

A synthetic test illustrated that even a sand lens with a thickness of $0.12 \mathrm{~m}$ was apparent from the EM wave velocity profile when a dense sampling of the measurements was applied. It was not possible to identify the slope of the sand lens or whether it was coherent using a one- 
dimensional measurement survey (i.e. ZOP). Nevertheless, the synthetic GPR data were affected by the vertical clay section intersecting the sand layer, and this information content may potentially be exploited using a two-dimensional measurement survey (i.e. MOG) in combination with more advanced data analysis.

Finally, a FWI algorithm was used to illustrate that the GPR data also contains information regarding variability within the clayey till that could correlate to more sandy and therefore more hydraulic conductive areas.

\section{ACKNOWLEDGMENTS}

This work is a result of a collaboration project between University of Copenhagen, Orbicon, and Capital Region of Denmark, and was funded by Capital Region of Denmark. Peer Jørgensen is greatly thanked for help in the field.

\section{REFERENCES}

Annan, P. A., 2005, GPR methods for hydrogeological studies, in Y. Rubin and S. S. Hubbard, eds., Hydrogeophysics, Springer, Netherlands, 185-213.

Binley, A., P. Winship, L. J. West, M. Pokar, and R. Middleton, 2002, Seasonal variation of moisture content in unsaturated sandstone inferred from borehole radar and resistivity profiles, Journal of Hydrology, 267, 160-172.

Broholm, K., B. Nilsson, R. C. Sidle, and E. Arvin, 2000, Transport and biodegradation of creosote compounds in clayey till, a field experiment, Journal of Contaminant Hydrology, 41, $239-260$. 
Cassiani, G., V. Bruno, A. Villa, N. Fusi, and A. M. Binley, 2006, A saline trace test monitored via time-lapse surface electrical resistivity tomography, Journal of Applied Geophysics, 59, 244-259.

Ernst, J. R., H. Maurer, A. G. Green, and K. Holliger, 2007, Full-Waveform Inversion of Crosshole Radar Data based on 2-D Finite-Difference Time-Domain Solutions of Maxwell's Equations, IEEE Transactions on Geosciences and Remote Sensing, 45, no. 9, 2807-2828, doi:10.1109/TGRS.2007.901048.

Gerlitz, K., M. D. Knoll, G. M. Cross, R. D. Luzitano, and R. Knight, 1993, Processing ground penetrating radar data to improve resolution of near-surface targets, Proceeding of the Symposium on the Application of Geophysics to Engineering and Environmental Problems, San Diego, California.

Gueting, N., A. Klotzsche, J. van der Kruk, J. Vanderborght, H. Vereecken, and A. Englert, 2015, Imaging and characterization of facies heterogeneity in an alluvial aquifer using GPR full-waveform inversion and cone penetration tests, Journal of Hydrology, 524, 680-695, doi:10.1016/j.jhydrol.2015.03.030.

Graversen, P., I. M. Balling, G. Vignoli, K. E. S. Klint, W. Brüsch, B. Nilsson, C. L. Larsen, R. Juhler, and A. E. Rosenbom, 2014, Vurdering af mulighederne for udpegning af pesticidfølsomme lerområder (SFO-ler) på grundlag af eksisterende data, Danmarks og Grønlands Geologiske Undersøgelse Rapport, 2014/2, GEUS. 
Haarder, E. B., K. H. Jensen, A. Binley, L. Nielsen, T. B. Uglebjerg, and M. C. Looms, 2015, Estimation of recharge from long-term monitoring of saline tracer transport using electrical resistivity tomography, Vadose Zone Journal, 14, no. 7, doi:10.2136/vzj2014.08.0110.

Houmark-Nielsen, M., 1989, The last interglacial-glacial cycle in Denmark, Quaternary International, 3/4, 31-39.

Houmark-Nielsen, M., 2007, Extent and age of Middle and Late Pleistocene glaciations and periglacial episodes in southern Jylland, Denmark, Geological Survey of Denmark and Greenland Bulletin, 55, no. 1, 9-35.

Houmark-Nielsen, M., 2010, Extent, age and dynamics of marine isotope stage 3 glaciations in the southwestern Baltic Basin, Boreas, 39, no. 2, 343-359.

Hubbard, S. S., J. E. Peterson, E. L. Majer, P. T. Zawislanski, K. H. Williams, J. Roberts, and F. Wobber, 1997, Estimation of permeable pathways and water content using tomographic radar data, The Leading Edge of exploration, 16, no. 11, 1623-1628.

Irving, J.D., and R.J. Knight, 2005, Effect of antennas on velocity estimates obtained from cross-borehole GPR data, Geophysics, 70, no. 5, K39-K42.

Irving, J., and R. Knight, 2006, Numerical modeling of ground-penetrating radar in 2-D using MATLAB, Computers \& Geosciences, 32, 1247-1258.

Irving, J. D., M. D. Knoll, and R. J. Knight, 2007, Improving crosshole radar velocity tomograms: A new approach to incorporating high-angle traveltime data, Geophysics, 72, no. 4, J31-J41, doi: 10.1190/1.2742813. 
Jakobsen, P. R., and K. E. S. Klint, 1999, Fracture distribution and occurrence of DNAPL in a clayey lodgement till, Nordic Hydrology, 30, no. 4/5, 285-300.

Jupiter database. Denmark’s geological and hydrological database. http://www.geus.dk/DK/data-maps/jupiter

Jørgensen, P. R., M. Hoffmann, J. P. Kistrup, C. Bryde, R. Bossi, and K. G. Villholth, 2002, Preferential flow and pesticide transport in a clay-rich till: field, laboratory, and modeling analysis, Water Resources Research, 38, no. 11, 28-1-28-15.

Keller, C. K., G. Van Der Kamp, and J. A. Cherry, 1986, Fracture permeability and groundwater flow in clayey till near Saskatoon, Sasketchewan, Canadian Geotechnical Journal, 23, 229-240.

Keskinen, J., A. Klotzsche, M. C. Looms, J. Moreau, J. van der Kruk, K. Holliger, L. Stemmerik, and L. Nielsen, 2017, Full-Waveform Inversion of Crosshole GPR Data: Implications for Porosity Estimation in Chalk, Journal of Applied Geophysics, 140, 102-116, doi: 10.1016/j.jappgeo.2017.01.001.

Kessler, T. C., 2012, Hydrogeological characterization of low-permeability clayey tills the role of sand lenses: PhD thesis, Technical University of Denmark.

Kessler, T. C., K. E. S. Klint, B. Nilsson, and P. L. Bjerg, 2012, Characterization of sand lenses embedded in tills, Quaternary Science Reviews, 53, 55-71, doi: 10.1016/j.quascirev.2012.08.011. 
Klint, K. E. S., and P. Graversen, 1999, Fractures and biopores in Weichselian clayey till aquitards at Flakkebjerg, Denmark, Hydrology Research, 30, no. 4-5, 267-284.

Klotzsche, A., J. van der Kruk, G. A. Meles, J. Doetsch, H. Maurer, and N. Linde, 2010, Full-waveform inversion of cross-hole ground-penetrating radar data to characterize a gravel aquifer close to the Thur River, Switzerland, Near Surface Geophysics 8, no. 6, 635-649. doi: 10.3997/1873-0604.2010054.

Klotzsche, A., J. van der Kruk, J. Bradford, and H. Vereecken, 2014, Detection of spatially limited high-porosity layers using crosshole GPR signal analysis and full-waveform inversion, Water Resources Research, 50, doi:10.1002/2013WR015177.

Looms, M. C., K. H. Jensen, A. Binley, and L. Nielsen, 2008, Monitoring unsaturated flow and transport using cross-borehole geophysical methods, Vadose Zone Journal, 7, 227-237, doi: 10.2136/vzj2006.0129.

McCabe, A. M., 1987, Quaternary deposits and glacial stratigraphy in Ireland, Quaternary Science Reviews, 6, 259-299.

McKay, L. D., J. A. Cherry, and R. W. Gillham, 1993, Field Experiments in a fractured clay till 1. Hydraulic conductivity and fracture aperture, Water Resources Research, 29, no. 4, 1149-1162.

Meles, G. A., J. van der Kruk, S. A. Greenhalgh, J. R. Ernst, H. Maurer, and A. G. Green, 2010, A new vector waveform inversion algorithm for simultaneous updating of conductivity 
and permittivity parameters from combination crosshole/borehole-to-surface GPR Data, IEEE Transaction on Geoscience and Remote Sensing, 48, no. 9.

Meles, G., S. Greenhalgh, J. van der Kruk, A. Green, and H. Maurer, 2011, Taming the non-linearity problem in GPR full-waveform inversion for high contrast media, Journal of Applied Geophysics, 73, no. 2, 174-186, doi:10.1016/j.jappgeo.2011.01.001.

Nilsson, B., R. C. Sidle, K. E. Klint, C. E. Boggild, and K. Broholm, 2001, Mass transport and scale-dependent hydraulic tests in a heterogeneous glacial till - sandy aquifer system, Journal of Hydrology, 243, 162-179.

Oberröhrmann, M., A. Klotzsche, H. Vereecken, and J. van der Kruk, 2013, Optimization of acquisition setup for cross-hole GPR full-waveform inversion using checkerboard analysis, Near Surface Geophysics, 11, 197-209, doi: 10.3997/1873-0604.2012045.

Shaw, J., 1987, Glacial sedimentary processes and environmental reconstruction based on lithofacies, Sedimentology, 34, no. 1, 103-116.

Sidle, R. C., B. Nilsson, M. Hansen, and J. Fredericia, 1998, Spatially varying hydraulic and solute transport characteristics of a fractured till determined by field tracer tests, Funen, Denmark, Water Resources Research, 34, no. 10, 2515-2527.

van der Kruk, J., C. M. Steelman, A. L. Endres, and H. Vereecken, 2009, Dispersion inversion of electromagnetic pulse propagation within freezing and thawing soil waveguides, Geophysical Research Letters, 36, L18503, doi:10.1029/2009GL039581. 


\section{LIST OF FIGURES}

Figure 1. a) The zero-offset profile collected between borehole RT1 and RT3, along with analyzed EM velocity and amplitude profiles. The raw data and the interpreted drill cuttings are included to enable direct comparison. b) - d) Synthetic analysis using the forward solver in the FWI routine. ZOP data for three synthetic models are produced: b) Assuming a coherent sand layer between borehole RT1 and RT3. c) Model including a thin $(0.12 \mathrm{~cm})$ horizontal sand layer. d) Assuming that the sand layer is interrupted by a $0.12 \mathrm{~m}$-thick clay "layer" halfway between the boreholes. The grey lines in c) and d) are the results of Synthetic model 1, and are included to facilitate direct comparison. In a) and b) an asterisk marks the depth of constructive interference between the direct EM wave travelling through the clayey till and the critically refracted head wave emitted from the fast-traveling wave in the sand layer.

Figure 2. Two-dimensional data analysis. a) Simple amplitude analysis using the first positive peak of the multiple-offset gather collected between borehole RT1 and RT3. The color coding represents a binary subsurface of sand and clayey till assuming a cut-off amplitude value of $15000 \mathrm{mV}$. The electromagnetic wave is in the plot assumed to travel the shortest direct path. The drill cuttings are included to enable comparison. b) - c)The starting models and the subsurface models after running the FWI algorithm 10 iterations. The top panel presents the electromagnetic wave velocity images, while the lower panel presents the electrical conductivity images. The black dashed lines mark the boundary of the muted zone around the boreholes. The full-waveform inversion procedure does not alter the physical properties of the subsurface within the muted zone and therefore retain the properties of the starting model. 

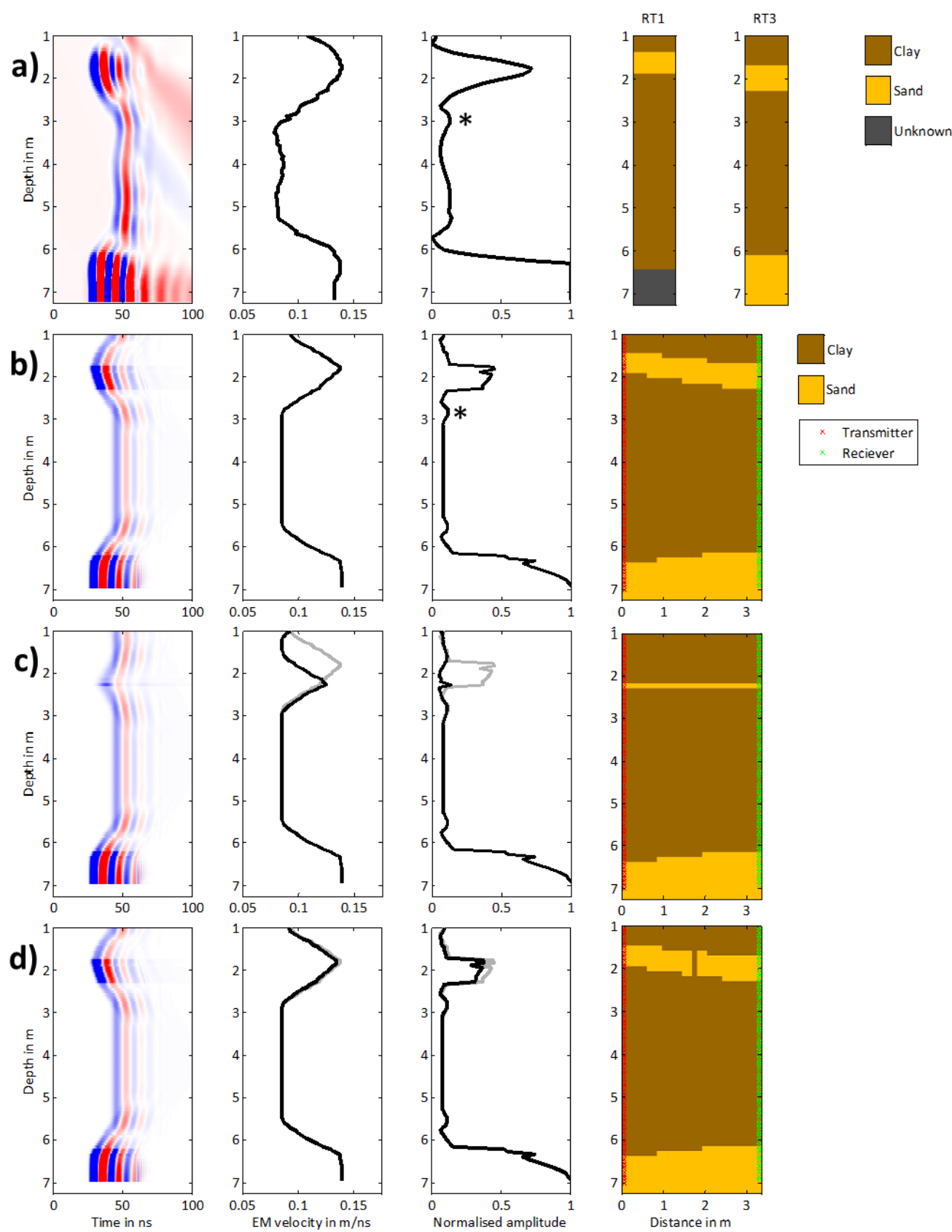

Figure 1. a) The zero-offset profile collected between borehole RT1 and RT3 (leftmost), along with analyzed EM velocity (second from left) and amplitude profiles (third from left). The raw data and the interpreted drill cuttings are included to enable direct comparison. b) - d) Synthetic analysis using the forward solver in the FWI routine. ZOP data for three synthetic models are produced: b) Assuming a coherent sand layer between borehole RT1 and RT3. c) Model including a thin $(0.12 \mathrm{~cm})$ horizontal sand layer. d) Assuming that the sand layer is interrupted by a 0.12 m-thick clay "layer" halfway between the boreholes. The grey lines in c) and d) are the results of Synthetic model 1, and are included to facilitate direct comparison. In a) and b) an asterisk marks the depth of constructive interference between the direct EM wave travelling through the clayey till and the critically refracted head wave emitted from the fast-traveling wave in the sand layer. 

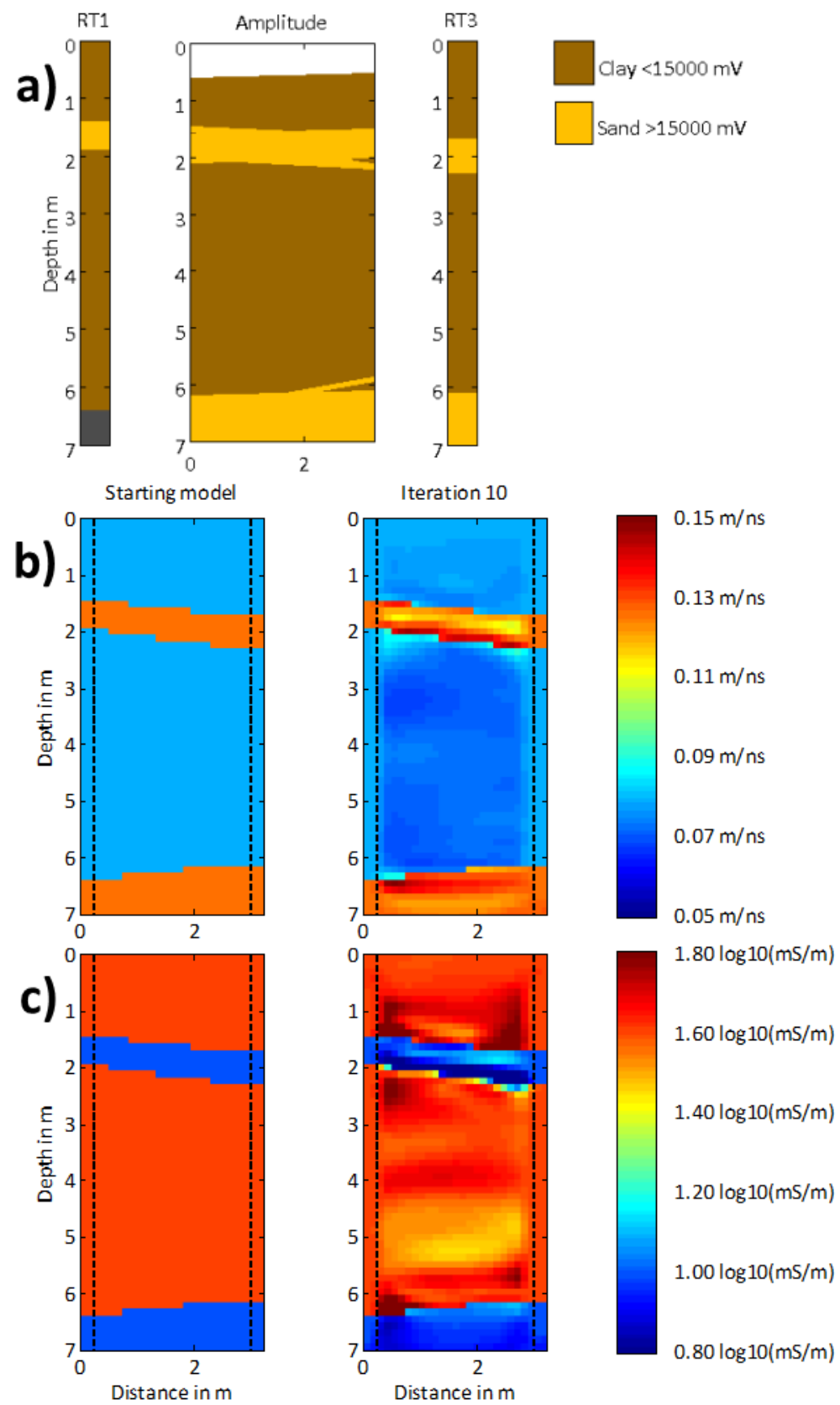

Figure 2. Two-dimensional data analysis. a) Simple amplitude analysis using the first positive peak of the multiple-offset gather collected between borehole RT1 and RT3. The color coding represents a binary subsurface of sand and clayey till assuming a cut-off amplitude value of $15000 \mathrm{mV}$. The electromagnetic wave in the plot is assumed to travel the shortest direct path. The drill cuttings are included to enable comparison. b) - c) The starting models and the subsurface models after running the FWI algorithm 10 iterations. b) presents the electromagnetic wave velocity images, while c) presents the electrical conductivity images. The black dashed lines mark the boundary of the muted zone around the boreholes. The FWI procedure does not alter the physical properties of the subsurface within the muted zone and therefore retains the properties of the starting model. 